\title{
RURALIDAD Y "FRONTERA INTERIOR" EN LA PATAGONIA CHILENA: UNIDADES DOMÉSTICAS, VIDA COTIDIANA Y NUEVOS EJES PARA SU COMPRENSIÓN
}

\author{
JUAN C. RODRÍGUEZ T.a JUAN A. SÁENZ P. ${ }^{\mathrm{b}}$, \\ NICOLÁS GISSI B. ${ }^{c} \&$ FERNANDO MANDUJANO B. ${ }^{\circledR}$
}

\section{RESUMEN}

La Patagonia chilena posee un conjunto de características que la hacen claramente distinguible frente a otras regiones, lo que está dado por sus atributos naturales, la escasa diversificación de sus actividades productivas y la percepción de lejanía respecto de los lugares donde se toman las decisiones que afectan a sus habitantes. Una baja densidad demográfica, vías de desplazamiento mal servidas, escasa dotación de servicios y dependencia alimentaria, hacen que gran parte de las relaciones políticas y simbólicas de esta bio-región sean sólo formales respecto del Estado, ya que se configura más bien un país de tipo horizontal que longitudinal, cuyos sistemas de referencia se encuentran en ciudades de Argentina. Estos aspectos que definen las condiciones del habitar, junto a las nuevas formas de apropiación territorial y distintas modalidades de inversión, constituyen los elementos de discusión que ayudan a problematizar el proceso de reterritorialización rural de la Patagonia, en el país más neoliberal del continente. Presentamos en estas páginas un análisis de la Patagonia norte chilena a partir del método etnográfico, preguntándonos por la vida cotidiana de sus unidades domésticas.

PALABRAS CLAVE: Patagonia, Estado, territorio, naturaleza, aislamiento.

\section{RURALITY AND "INTERIOR BORDER" IN THE CHILEAN PATAGONIA: DOMESTIC UNITS, DAILY LIFE AND NEW AXES FOR UNDERSTANDING}

\section{ABSTRACT}

The Chilean Patagonia possess a number of characteristics that makes it clearly distinguishable among other regions, such as its natural attributes, the scarce diversification of productive activities and perception of remoteness from the places where decisions that affect their inhabitants are taken. A low population density, poorly served roads, poor provision of services and food dependency, provokes that much of the political and symbolic relationships of this bio-region are only formal in relation to the State.

\footnotetext{
CINVIT-Escuela de Diseño, Universidad de Valparaíso. $\rangle$ juan.rodriguezt@uv.cl

Universidad de Chile. jsaenzpas@gmail.com

Departamento de Antropología, Universidad de Chile.ngissi@uchile.cl

Facultad de Educación, Universidad de Playa Ancha.fm@upla.cl
} 
They consigure a horizontal rather than a longitudinal country, whose reference systems are located in Argentinian towns. These aspects that define the conditions of living, together with new forms of territorial appropriation, and different forms of investment, constitute the elements of discussion used to problematize the process of rural reterritorialization of Patagonia in the most neoliberal country on the continent. We present here an analysis of the north Chilean Patagonia using an ethnographic method, asking about the daily life of their domestic units.

KEY WORDS: Patagonia, State, territory, nature, isolation.

\section{INTRODUCCIÓN}

En la Patagonia chilena, especialmente en Palena y Aysén, existen algunas particularidades que son importantes de considerar para un país políticamente unitario y regionalizado desde la perspectiva de la ruralidad, lo que se puede sintetizar en las siguientes ideas: 1) una densidad demográfica inferior a un habitante por kilómetro, en un territorio equivalente a un tercio de la superficie total del país; 2) un Estado centralizado que dificulta el desarrollo económico y la autonomía con la imposición de políticas que no consideran adecuadamente las condiciones locales; 3) sus habitantes dentro de un Estado fallido (Migdal, 2016) operan binacionalmente para satisfacer demandas médicas, alimentarias, laborales, educacionales y recreativas; 4) se vive aisladamente en las pequeñas comunidades, ya que no existen los kilómetros lineales por la abrupta geografía, la adversidad de condiciones climáticas y frecuentes cortes de camino; 5) los municipios cuentan con escaso o nulo poder de negociación frente a la autoridad regional y nacional, generándose también relaciones centroperiferia en la región; 6) importantes dificultades para contratar profesionales; 7) poca masa crítica por la ausencia de centros de investigación; 8) no existen vías terrestres estructurantes efectivas que le conecten con el resto del país, lo que obliga al uso de barcazas y avión, o rutas argentinas para el desplazamiento hacia el norte; 9) se encuentra actualmente presionada por imaginarios globales que visualizan su territorio como uno de los últimos lugares del planeta donde quedan tierras disponibles y diversos recursos en abundancia de interés para el capital (Rodríguez et al. 2012; Rodríguez et al. 2015).

La ruralidad patagónica, circunscrita en este caso a la Patagonia-Palena y Patagonia-Aysén (entre el paralelo $42^{\circ}$ hasta el $49^{\circ} 16^{\prime}$ ), es decir, el área de influencia de la Carretera Austral, está históricamente condicionada por su accidentada geografía (lagos, ríos, bosques, acantilados) y ausencia de caminos primarios y secundarios permanentemente transitables. En el pasado, en su período económico ovejero, no favorecía el movimiento de los animales y los fardos de lana desde la zona alta (frontera con Argentina) a la costa con fines de exportación al centro del país, asî como el abastecimiento de alimentos en dirección contraria. Esto se transformó en una escasa diversificación productiva, que no permitió por cuestiones ambientales, tecnológicas y logísticas el desarrollo de la agricultura como recurso autónomo y soberano (CORFO, 1950, 1960).

Las dificultades de realizar expeditamente el tránsito longitudinal y horizontal de personas y mercancías por territorio continental, terminan por definir una condición interior de vida al "límite" -señala un SEREMI- y un importante aislamiento, que define a la región a partir de un determinismo geográfico para justificar por qué es la última en integrarse a la geografía económica nacional (CORFO, 1950, 1960); y luego, establecerla en una nomenclatura contemporánea, como una "Frontera Interior" (Ministerio de Defensa Nacional, 2010; Masalleras y Ortega, 2012; Correa \& Salas, 2015).

Lo señalado, inevitablemente lleva a la idea de que la Patagonia se constituye tempranamente en una suerte de país aparte, argumentación que es desarrollada a través de un conjunto de apreciaciones y análisis sobre las acciones de la política pública y los funcionarios del Estado, por parte del diplomático y escritor Víctor Domingo Silva, cónsul chileno en Bariloche y Chubut. Éste, un importante cronista, de gran conocimiento y un testigo privilegiado de los cambios en los intersticios del territorio patagónico chileno y argentino, recoge -en "La tempestad se avecina" (1936)- las grandes diferencias y desequilibrios 
entre el proceso de chilenización y argentinización de la Patagonia, sosteniendo que el ímpetu material y simbólico de los argentinos haría muy vulnerable a la población nacional de las zonas fronterizas. Marcando el énfasis en que la vulnerabilidad debe ser entendida en la perspectiva de que las poblaciones fronterizas, desconectadas de los centros político administrativos, no responden a identidades de tipo nacional, o que éstas no son ni argentinas ni chilenas, y que en lo ordinario circulan de un lado a otro de la baja cordillera, a partir de una red laboral y familiar de tipo político y consanguíneo.

Esta idea está directamente relacionada con la iniciativa del Presidente Carlos Ibáñez, que decreta la creación del "territorio de Aysén", en 1928, con capital en Puerto Aysén. El acto fundacional se realiza sobre una organización territorial anterior, que toma como base la asignación de tierras de grandes magnitudes a empresas ganaderas, las que ocuparon "tierras vacías". Esa condición, que había sido la única forma colonizadora para sostener soberanía territorial de una zona poco conocida y que había sido descrita hace un par de décadas atrás por el geógrafo Hans Steffen (2015), contribuyó a generar un gran mosaico disperso de pequeños agrupamientos y localidades, y condenó a los pobladores al estar separados por importantes distancias; forjó, además, una lógica de ocupación autovalente y una singularidad muy entrópica de la sociabilidad, la que impuso importantes enclaustramientos que no fomentaron las interacciones e integraciones territoriales en la parte chilena.

Con un conjunto de déficits, y desconocidos los modos de vida en su cotidianeidad desde el centralismo político, el territorio se concreta en la idea potente de una bio-región marcada por sus ecosistemas; $y$, social y culturalmente en una autonomía de sus prácticas cotidianas y formas de resolución de problemas, las que se encuentran más allá de la comunidad imaginada, imaginario de nación o ficción historiográfica en los términos de Anderson (2006). O, como sostiene Migdal (2011), en dificultades, a pesar de los esfuerzos, para profundizar en una organización dominante y coherente en el territorio, así como identificar las partes, modos y prácticas de funcionamiento de sus múltiples unidades burocráticas y administrativas. De este modo, fue y es un lugar de distancias largas, de unidades productivas rurales separadas unas de otras, con pocos caminos pavimentados y tránsito difícil, con vías estructurales muy recientes como la Carretera Austral ${ }^{1}$, por lo que aún existen sectores no penetrados y desconocidos en su cotidianeidad; a lo que se adiciona una percepción local de mucha "tierra libre" y "disponible", de importante diversidad ecológica y con áreas de poca o ninguna intervención humana.

Conforme a estos lineamientos y avalado por un trabajo de campo realizado entre los años 2012 y 2016, lo que se presentará etnográficamente y discutirá etnológicamente son algunos de los particularismos de la ruralidad patagónica que corresponde a lo que denominaremos "Frontera Interior", como un espacio de desconexión del imaginario país y donde "más del $50 \%$ de la población desempeña actividades primarias" (SUBDERE, 2008, p. 8), en la idea de una frontera que reúne los atributos antes descritos y que se encuentra en proceso de reorganización territorial, conforme a prácticas de Estado, actores locales y extralocales (ambientalistas e inversores) e imaginarios nacionales y globales que tensionan las vidas localizadas de las unidades domésticas.

\section{MARCO REFERENCIAL: LA NUEVA RURALIDAD LATINOAMERICANA}

En la actualidad, pocos discuten que a partir de los análisis de la geografía de los años 70's, y en lo que va del desarrollo de las geografías críticas a las que asistimos desde los 90's hasta hoy, existe desde la perspectiva analítica una importante resignificación de los procesos de territorialización,
1 La Carretera Austral, si bien es la obra pública más importante en términos de inversión y es altamente valorada por la población de la Patagonia-Palena y Patagonia-Aysén, tiene dos dificultades: 1) en gran parte va por la costa y no por el interior, lo que hace que las localidades fronterizas como Palena, Futaleufú, Lago Verde y La Tapera queden fuera de ruta; 2) que iniciar un viaje por las zonas pavimentadas o ripiadas, no implica que éste se pueda ejecutar completo; los derrumbes, caídas de árboles y desbordes de cauces, son frecuentes y es imposible tener absoluto control del viaje. De hecho, las guías internacionales de turismo, le indican a los viajeros que la certeza de un viaje en bus sólo se confirma en la ventanilla de venta de pasajes. 
los que hoy son entendidos en términos dinámicos y relacionales, producto de formas de poder establecidas en distintas escalas físicas y económicas. Dentro de los marcos de la globalización, este poder se ha localizado en la Patagonia por medio de intereses particulares, diversos y contradictorios frente a actividades tradicionales, como acontece por ejemplo con el turismo exclusivo y/o ecolujo, parcelaciones, creación de parques privados, venta de bonos de carbono, el aprovechamiento de los recursos hídricos (para consumo y producción de energía), la madera y la minería, o el control de estuarios para el desarrollo acuícola; generando una imagen multitemporal (valores pre modernos hasta posmaterialistas), la producción de desigualdades socio-espaciales (demográficas, económicas, sociales y culturales) y zonas de sacrificio (ambiental y demográfico), como efecto de la dominación material y simbólica y la distinta valorización de los activos existentes en el espacio o el territorio (Lapes De Souza, 2000; Santos, 2000; Schejtman \& Berdegué, 2003; Haesbaert, 2004; Harvey, 2004, 2014).

En este sentido, el territorio patagónico mantiene una tensión entre el pensamiento de frontera y de posfrontera. El primero, ligado a procesos potenciales de descubrimiento, conquista y extracción de recursos, que de acuerdo a la experiencia modifica radicalmente las localidades y sus memorias a través de tecnologías y la presencia de nuevos actores; el segundo, asociado a modalidades de reconocimiento, protección ambiental y salvaguardas sociales, que modifican las reglas del juego en términos productivos al incorporar elementos de derecho y reconocimiento a las localidades afectadas, así como derechos a otros seres vivos (Larsen, 2016, pp. 24-25). Con ello, reconociendo el distinto peso específico de las comunidades, Estado y privados, se produce un tránsito desde lo espacial como paisaje a lo territorial como sistemas de acciones y objetos (Santos, 2000), mutando en ambas vertientes las actividades, memorias y subjetividades de la población en lo que significa el proceso de realización de la existencia.

Así, aparecen formas y campos diversos en los que se canalizan las relaciones de poder para limitar y delimitar los territorios y marcos de acción posibles, estableciendo nuevas constelaciones materiales y simbólicas que operan como polos de atracción, expulsión y retención, generando condiciones de territorialización, desterritorialización y reterritorialización de la población y sus actividades (véase Haesbaert, 2004). Esto, siempre de la mano del repertorio de alternativas y posibilidades de flexibilización con el que cuentan las comunidades, especialmente las aisladas y vulnerables, cuando son especializadas y se han constituido como culturas del trabajo como es la actividad ganadera (destinada a consumo o lanar) y forestal (madera aserrada o con fines combustibles).

En este punto, reconocemos que en la actividad ganadera y maderera se constituyen cuestiones invariables del modo de vida que están siendo afectadas, y que son propias de la cultura del trabajo. Se trata de un sistema organizativo cíclico para la producción, que articula los medios disponibles y los objetos de producción, los que activan una praxis específica y modos de vivir inter e intrageneracionales coherentes con esa exigencia. En particular, la construcción del territorio se produce por el trabajo criancero de ovejas, las que son considerada productivas entre 4 y 7 años; comenzando con la parición en primavera, destinando una parte a la venta de carne y otra a la reproducción. A los dos meses los animales son marcados para su identificación; los capones son separados para la producción de lana, y las ovejas de los carneros. Luego sigue la esquila, y el baño para liberarlos de los ectoparásitos (sarna ovina). Los animales son devueltos al campo, los nuevos son destetados y nuevamente separados por su condición de fertilidad: borrego/a, carneros, corderos y capones. Asimismo, en paralelo se produce la restauración de cercos, el cuidado del rebaño frente a depredadores, la protección del mismo cuando las condiciones climáticas se vuelven muy adversas y la rotación de pastizales. Al final, la venta será otro proceso.

"El monte" (el bosque) juega otro papel central. Es imposible la reproducción sin los productos madereros y no madereros; está el monte que "se tira" o "voltea", se seca y se aserra para convertirlo en producto maderable; y "el monte" transformado en leña, que se usa como energía para calefaccionar, cocinar, secar la ropa y "matear" como dimensión ritual de la sociabilidad. Se trata de 
una actividad permanente y regular dentro del ciclo anual, ya sea para el autoconsumo, la venta o el intercambio, principalmente la segunda.

En este sentido, los registros de campo señalan que ambas actividades implican una inscripción de la cultura en el espacio, una distribución de prácticas e institucionalidad en el espacio, y una subjetividad expresada como apego y pertenencia que estructura el territorio y el tiempo productivo y familiar.

De cara a estas marcas de inscripción de la cultura en el espacio como representación de un modo de vida, hemos expresado en otros trabajos las dificultades que estas actividades comportan en la actualidad (Rodríguez et al. 2015, 2016), especialmente por el peso que alcanza la redefinición del territorio desde el punto de vista de la adquisición de tierras, asociada a la concepción de la "ecología profunda", con la presencia del fallecido ambientalista Douglas Tompkins. El interés filosófico por llegar al disclimax como proceso restaurativo de los ecosistemas, implica la expulsión de ganaderos y de toda la fauna exógena de las tierras privadas y consagradas como parques; lo mismo, frente a la necesidad cotidiana de hacer uso del bosque. Asimismo, otras limitaciones de actividades tradicionales se asocian a eco-corretajes; que son parcelaciones de bajo impacto en edificación, sin actividades invasivas y con tierras de protección en comunidad, que limitan también la participación de las culturas del trabajo locales que requieren de uso extensivo del territorio ${ }^{2}$. Otra fórmula, es la venta de bonos de carbono, a través de la plantación de bosque nativo. Todas ellas se conjugan con sus matices en la protección del "Gran Otro" (naturaleza), no al "otro residente" (op. cit.).

Sin duda, el turismo también implica limitaciones y contradicciones para la población local, ya que su oferta para un importante segmento de visitantes es de exclusividad, conjugación sensorial y armonía. Y, cuando el interés está asociado a segmentos de altos ingresos, clase mundial y de orientación verde, lo que "se quiere" y "vende" es una suerte de jurassic park. Así, se

2 Se trata de un modelo de construcción del territorio, orientado hacia la conservación a través de un negocio autofinanciado como la emisión de bonos de carbono, en el que personas naturales compran una membresía y impone como interfaz el ecolujo como expresión de arquitectura, representando una expresión de formas orgánicas, de sobriedad y belleza sostenible que se incorpora al paisaje detenido en el tiempo. Como ideas fuerza, apunta por un lado, a reforzar la experiencia del habitar más que la de sentirse en un recinto ajeno, con privacidad y espacios amplios, con silencio íntimo, generando una calidez que rompe con la intemperie de lo natural que se ubica tras el cristal; por otro, en términos de diseño, se caracteriza por el desarrollo de un interiorismo sustentado en materiales nobles (maderas, algodón, lana, cuero), combinado con antigüedades locales $\mathrm{u}$ objetos de arte sencillos que manifiestan continuidad de los materiales, con una búsqueda de la luminosidad que ofrece la profundidad del campo. La conjugación entre la experiencia interior y exterior acentúa el sentimiento de admiración por la naturaleza, privilegiando las posibilidades de la mirada, atrapando las vistas profundas, con sus letanías y paletas de colores; asimismo, acercando sin intervenciones la fuerza y forma de las montañas, el agua, la lluvia, los colores, la estepa, el bosque y la fauna. Con ello, las edificaciones bajo control de factores como la ventilación, la temperatura y la entrada de la luz, se integran al entorno de manera no invasiva y dejan entrar lo telúrico del exterior. La belleza interior y exterior ofrecen armónica continuidad; un goce único, perenne, para alimentar la memoria de por vida y para que la naturaleza permanezca inviolada.

$\mathrm{Si}$ se rescatan estas territorializaciones que funcionan como enclaves económicos y de belleza, hay un principio conservacionista incompatible con el extractivismo, pero reforzado como generador de rentas por la fragmentación de la presencia humana. La condición sui generis y superlativa que alcanzan los lugares seleccionados y los equipamientos del proyecto de ecolujo, y la puesta en valor de los ecosistemas y el paisaje en el mercado de las especulaciones a nivel internacional, sumado a las prácticas de una comunidad como condensación de su temporalidad puesta en valor (fiesta, rito y actividades cotidianas), conducen a que las periferias territoriales puedan convertirse en

se incorporan a una comunidad que controla importantes extensiones de tierra de gran belleza escénica (Rodríguez et al. 2018). 
centros de interés y de negocios. Esto muestra que no son países los más importantes; son ciudades, regiones o localidades fuera de ruta, inclusive donde no existe el cajero automático o se pierde la señal del celular. Así, el valor del lugar en la perspectiva de la Patagonia debe ser entendido en el marco de las transformaciones del capitalismo y sus propias contradicciones entre lo verde y el extractivismo, en la búsqueda permanente de oportunidades y nichos para generar valor.

Lo anterior, tiene un marco económico. Primero, porque existe una liquidez nunca observada para comprar o controlar áreas y territorios con fines diversos; segundo, el ingente movimiento del mercado de tierras a nivel mundial se allana a invertir en lo que no estaba en el imaginario económico y geográfico (Sassen, 2015), por lo que se produce localmente la convergencia y divergencia entre especulación, capitalismo extractivista y versiones verdes ${ }^{3}$. Es decir, se generan frentes de inversión posibles en varias direcciones, que pueden considerar actividades de explotación, especulativas de simple control, de conservación o filantrópicas bajo reglas privadas, así como otras ligadas a turismo exclusivo, en entornos escénicamente únicos.

Cualquiera sea la vía del modelo localizado, la condición no es inocua para las comunidades adyacentes del emprendimiento. Inclusive, los efectos pueden estar a miles de kilómetros de distancia, como cuando se venden bonos de carbono como compensaciones por contaminación o se declara el turismo como fundamento de una estrategia de desarrollo, sin considerar capacidad de carga local, huellas hídricas y de carbono. Este proceso, conforme a lo señalado por Sassen (2015), produce "expulsiones" nunca antes observadas para las posibilidades de reproducción de la vida local, al reorganizar el espacio y el territorio desde poderes verticales y desterritorializados, $y$ hacer muchas veces incompatibles actividades tradicionales y procesos modernizadores extractivistas $\mathrm{O}$ posmaterialistas.

3 La información que proporcionamos es en base a entrevistas a funcionarios de reparticiones directamente involucradas. Según SERNAPESCA, existen 720 concesiones acuícolas inscritas; SERNAGEOMIN registra 557 concesiones de explotación minera; SERNATUR tiene 18 lodges registrados, pero explican funcionarios que generalmente
Cuando bajo esta lógica se aborda el espacio rural norpatagónico, aparece una constelación inimaginable de combinatorias con la presencia de nuevos vecinos, y casos únicos producto de la variada gama de variables intervinientes de tipo tradicional, y otras nuevas o emergentes que fracturan el saber y hacer alojado en la memoria local. Y, aunque existen rasgos que permiten delinear algunas condiciones generales, los procesos localizados en la Norpatagonia resultan irreductibles a tipos ideales por cuestiones administrativas, demográficas, legales, de conectividad, condiciones ambientales y morfológicas, productivas, de mercado, tradiciones laborales y agenciamientos, las que expresan y fundan las relaciones global-local, nacional-local, regional-local.

Los procesos de mercantilización de la tierra, los cambios de uso del suelo, la transformación de los sujetos y la interpenetración de la urbe con su modelo industrial en el mundo agrícola y campesino, han dado paso a la consideración de la llamada Nueva Ruralidad Latinoamericana. Una conceptualización que apunta a re-escribir la relación entre los sujetos y los objetos de trabajo como acontece en labores agrícolas, ganaderas, forestales y pesquero artesanales como fuente de recursos para la reproducción social y biológica de las unidades domésticas que podemos observar en la Norpatagonia.

La Nueva Ruralidad queda definida por un tránsito de lo agrícola hacia lo agroindustrial y urbano, o al cambio de función, plurifunción y posición de los sujetos locales, lo que significa una alteración de las prácticas y la sociabilidad laboral y comunitaria, una reconstitución de las unidades productivas, de la cotidianeidad y sus rituales, y la forma de concebir y habitar el espacio. Por ello, la expresión de estas nuevas formas de ordenamiento y disposición constitutivas de las relaciones de trabajo y la sociabilidad tradicionales, opera desde un desanclaje total del tejido social a formas de rearticulación comunitarias en función de nuevos repertorios de posibilidades (Salas et al. 2011). En

\footnotetext{
estas instalaciones no se inscriben en el servicio de turismo, ya que prefieren mantener "bajo perfil" y el "anonimato de sus pasajeros". Entonces, lo estimable es que la cifra es superior, porque "el año 2012 existía un número de 65 en la región de Aysén".
} 
este sentido, autores como Barkin (2001), Bonnal, Díaz \& Losch (2004), Carton de Grammont (1999), Carton de Grammont y Martínez (2009), entre otros, han establecido que se trata de una modificación de las fronteras productivas; disputa de recursos, cambio de uso del suelo, especulación inmobiliaria, inversiones, pluri-actividad, diversificación, reconversión, des-campesinización, articulación a cadenas productivas y de servicios globales, alteraciones demográficas, participación de nuevos actores, nueva construcción social del espacio, trabajo extra-predial para completar ingresos, valorización y desvalorización del espacio, colonizaciones y neo-colonizaciones.

Lo señalado, reivindica la apreciación de la geografía críticay realza paralelamentela perspectiva socio-antropológica para la caracterización de los sujetos, las nuevas estratificaciones en términos localizados y las formas de negociación, control y poder que enfrentan en sus territorios. Con esta mirada se puede responder quiénes son o están siendo, qué hacen, cómo se proyectan y cuánto pueden controlar de su propia vida las poblaciones locales en un mundo marcado por la circulación de personas, bienes e imaginarios. Entonces, el territorio norpatagónico sometido a unas exigencias de pluri-actividad por actividades como el turismo, nueva propiedad de la tierra, constitución de áreas protegidas y venta de certificados de emisiones de bonos de carbono, deja de ser un problema de límites, lejanía y conectividad solamente. Es un problema que debe ser apreciado bajo consideraciones etnográficas y etnológicas sobre la amplitud espacial de las prácticas, ya que se están reconfigurando y tensionando los objetos de trabajo, mercados, ecosistemas y redefiniendo la posición del territorio y los sujetos en el mapa geoeconómico. En este sentido, mucho del acontecer localizado es consecuencia de lo que definiremos como "Frontera Interior". Un activo para algunos, una dificultad cotidiana para otros.

Más allá de campos del saber que han tratado de circunscribir territorialmente a las poblaciones con fines descriptivos y analiticos, las tradiciones rurales demuestran que la actividad implica siempre una importante vinculación con actores diversos para los procesos de intercambio simple o de mercado para la reproducción. Así, la territorialización es esencialmente una trama etnográfica de comportamientos institucionalizados y localizados, y espacialmente, con una amplitud establecida por actores y organizaciones con diferente poder político y económico, vinculados por actividades productivas y el mercado, bajo una modalidad contradictoria, regular y continuada (Manzanal, 2007).

\section{LINEAMIENTOS METODOLÓGICOS}

Los argumentos desarrollados para refrendar estas transformaciones territoriales en la Norpatagonia, están asociados a registros etnográficos basados en un conjunto de entrevistas semi-estructuradas realizadas a pequeños productores en sus lugares de emplazamiento en la Patagonia-Palena y Patagonia-Aysén.

Aunque el recorrido incluyó la Carretera Austral, desde el sur de Puerto Montt hasta Villa O`Higgins, y poblados argentinos como Trevelin, El Bolsón y Esquel, Teka, Río Mayo y Los Antiguos, el trabajo de campo más extenso se llevó a cabo en 14 comunas incluidas en cinco provincias: tres de Palena, en el extremo norte, y las 11 restantes pertenecientes a Coyhaique, Aysén, General Carrera y Capitán Prat. De todas ellas, las comunas de Chaitén, Futaleufú y Coyhaique fueron las más visitadas y - en distintas temporadas - sirvieron como localidades base.

Algunos entrevistados resultaron de encuentros casuales, pero otros fueron seleccionados conforme a la identificación de pluri-actividades que permiten la reproducción cotidiana y generacional de la unidad doméstica, especialmente ganaderas (vacunos y ovejas), madereras (leña), turismo rural, pescadores artesanales, transportistas y pequeños comerciantes. El objetivo de las entrevistas y los registros fue dar cuenta del tránsito de una ruralidad aislada, de consumo básico y orientada a la auto-reproducción, hacia la formación de una menos autónoma y recreada con expectativas ligadas al consumo; constituida a partir de la presencia de nuevos actores y fuerzas nacionales y globales modernizadoras (mineras, energéticas, acuícolas, turísticas, simbólicas y filosóficas) que están operando en el espacio y reconfiguran los procesos de territorialización, tensionando la posibilidad misma de la reproducción a nivel local. 
Paralelamente, se ha recogido información secundaria disponible en distintas bases de datos de instituciones del Estado, para discutirlas conforme a una hipótesis de trabajo, alojada en un programa de investigación sobre los procesos de construcción histórica y simbólica del territorio patagónico. En lo fundamental, ésta señala que Chile, país definido históricamente como una extensa y larga faja de tierra, no constituye un país unitario tal como es mostrado políticamente, sino que está conformado por un conjunto de islas continentales y no continentales configuradas por la accidentabilidad del desierto, los hielos eternos, el océano y la cordillera. La Patagonia, territorialmente constituiría una de estas islas continentales dentro de un archipiélago, donde las dificultades de conectividad lineal con el país "del centro" han sido permanentes, lo que ha reforzado la idea que en estos territorios se configura una autonomía simbólica, material y hasta política, constituyéndose un país distinto; de reciprocidad de tipo binacional y horizontal, política, económica y consanguínea, distante de chovinismos y la comunidad imaginada comprometida en la institucionalidad ${ }^{4}$.

Para desarrollar esta hipótesis, una entrada la ubicamos en el trabajo etnográfico, privilegiando una estrategia de registro multisituada, de modo de facilitar la imagen de co-construcción territorial, avalada por evidencia de participación de lugareños, actores locales institucionalizados y nuevos actores deslocalizados que afectan los contenidos tradicionales del territorio, así como las prácticas estatales. De este modo, triangulamos información para observar desplazamientos, percepciones de sujetos y sobre actores, observando la fidelización de los arraigos y estableciendo tendencias en la movilidad y las aspiraciones que van dando forma a esta frontera interior.

El registro de los datos se llevó a cabo con notas de campo, grabaciones de audio y fotografías,

4 Usamos la idea de lo binacional, no para afianzar la idea de lo nacional, y a través de ella la idea del "otro". Queremos resaltar la idea del país vivido por sobre el país político administrativo; es decir, cómo se superponen las formas distintas de producción del territorio, que difieren en los mundos que contienen y los movimientos propios de la vida, como constitución de la existencia física, social y simbólica. Y, es en este sentido, que las poblaciones más fronterizas usan el territorio en unir y venir como en el a lo cual se sumó archivos de prensa, bibliografía con reportes de estudios empíricos y documentos. Para sondear la extensión de algunas percepciones y expectativas de jóvenes terminando su educación media en liceos de las ciudades de Coyhaique y Aysén, se les aplicó durante el año 2016, una encuesta basada en muestra intencional, con un $\mathrm{n}=117$. Con ese vasto material se procuró la triangulación, y la validación como la calidad de la información.

\section{LA FRONTERA INTERIOR: ELEMENTOS DE DISCUSIÓN}

Como una amenaza a su integridad territorial, especialmente en el mundo militar que mantuvo la hipótesis de guerra con la República Argentina, Chile ha identificado históricamente diversas zonas desvinculadas del devenir político debido a dificultades de acceso y/o administración (Correa \& Salas, 2015). De esta evaluación que es política y logística, emergió en el lenguaje institucional, administrativo, académico y militar, un conjunto de conceptos y adjetivaciones tales como Zonas de Colonización, Zonas Extremas, Fronteras Interiores, Territorios Aislados y Territorios Especiales.

Desde la perspectiva del "lugar", utilizando como unidad comunas y localidades rurales y urbanas (Fig. 1), esta situación representa una condición endémica, ya que la población no percibe respuestas satisfactorias a necesidades $y$ deseos históricos de acompañamiento material y de servicios, lo que se ha traducido en un mundo invisibilizado y conflictos recientes, demandas de tratamiento especial de amplia repercusión frente a autoridades locales, regionales y nacionales, lo que hace transitar el déficit desde la condición de problema social a problema público ${ }^{5}$. Así, lo que está en juego es la capacidad de "obtener obediencia" -como señala Migdal (2008)-, en la

pasado anterior a las nacionalidades, y a las definiciones que algunas familias debieron tomar respecto de su identidad nacional, considerando una cuestión accidental la frontera, y no como un valor en sí mismo.

5 Se trata de demandas por salarios regionalizados, subsidios para alimentos, transporte, educación, energía, almacenes de zona franca y mejoras en los servicios del Estado, en una zona considerada $40 \%$ más cara que el resto del país. 


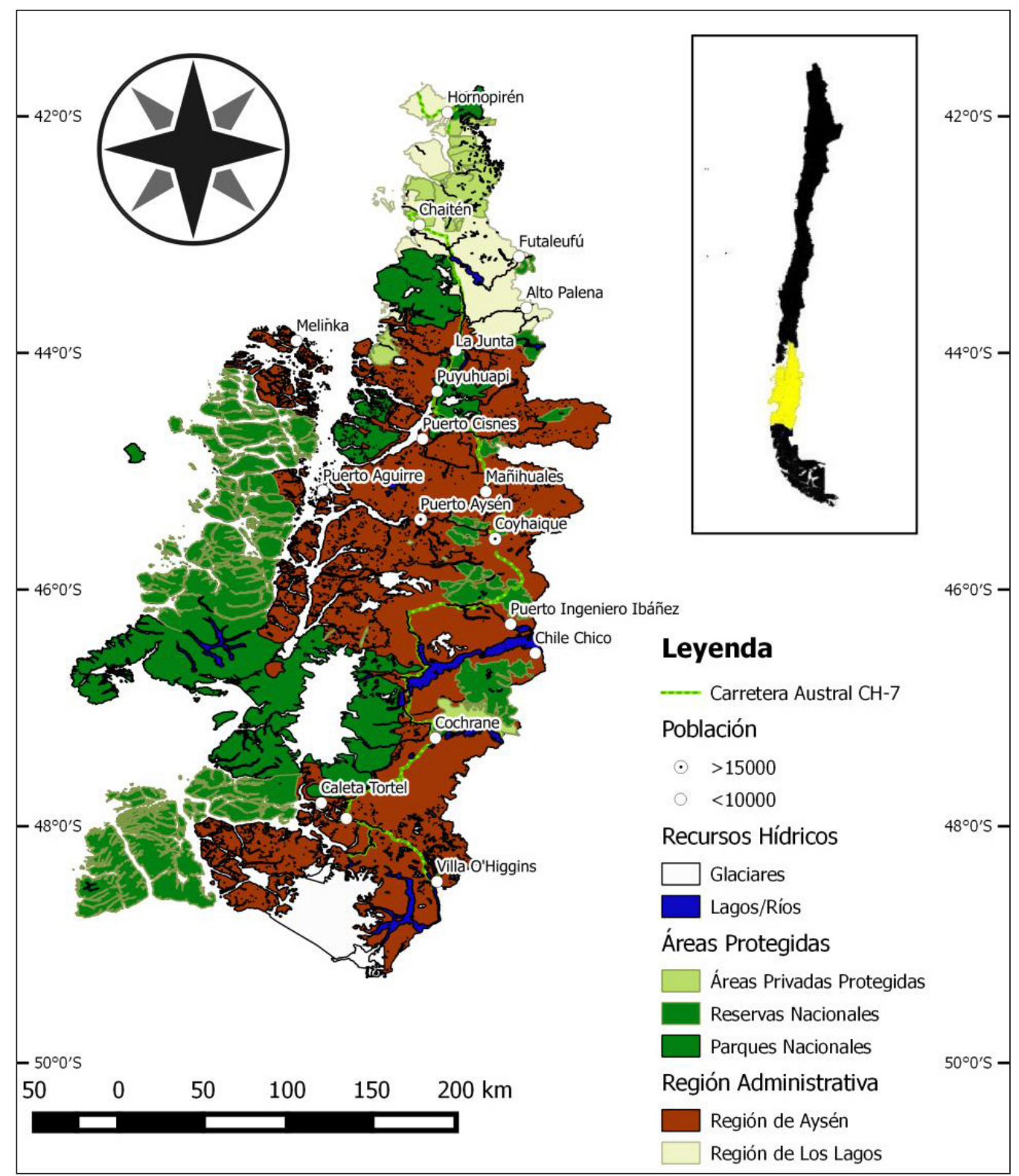

Elaboración: J. Sáenz, 2015

Fig. 1. Localidades, población y áreas de la Patagonia Nor-cental chilena.

medida que en la naturaleza del Estado está el de zonas caracterizadas por ser: proteger a quienes dice gobernar.

Desde la dictadura militar (1973-1989), estos territorios de menor atención comienzan a observarse con mayor celo por el riesgo que representan en el control de límites y por litigios fronterizos con Argentina y Perú. Nace así el concepto de "Frontera Interior", para dar cuenta
"Espacios terrestres -bajo la soberanía de Chile- no vinculados total $y$ efectivamente a la acción del gobierno central y/o regional, donde se dificulta el desarrollo de las actividades humanas y productivas por su distancia del núcleo vital 
y geohistórico del país, la ausencia de vías de comunicación, la influencia económica y cultural extranjera y la percepción ciudadana colectiva -en cada uno de los espacios geográficos- de constituir un ente diferente, separado $y / 0$ postergado del resto de la población nacional y que no alcanza a disfrutar del bienestar general debido a factores geográficos adversos" (Masalleras \& Ortega, 2012, p. 138).

Este concepto deconstruye incisivamente el imaginario de unidad nacional chileno, revelando en cambio una realidad territorial y simbólica fraccionada de norte a sur; o, si se quiere, mostrando un archipiélago geopolítico de difícil articulación y sintonía de unidad. Además de implicar serios "problemas de soberanía" para la lógica militar, fortalece el problema del aislamiento y acrecienta la auto-percepción de abandono con la presencia de barreras no sólo geográficas, sino económicas, sociales y culturales que indican un reparto desigual de equipamientos, bienes y servicios en términos de disponibilidad territorializada.

Es esta situación la que demanda una mirada analítica y reflexiva, para observar el efectivo tamaño de Chile en términos de integración y de sus centros y periferias, realzando la existencia de un Chile interior, poco estudiado y documentado en sus aspectos cotidianos. Releva modos de vida que funcionan con importante autonomía, con otras narrativas sobre la estructura estatal, con corredores binacionales y bidireccionales entre Chile-Argentina (Fig. 2), asociados a comercio, redes de parentesco político y consanguíneo, y culturas del trabajo que luchan por la sobrevivencia y retención de sus integrantes como acontece con las unidades familiares rurales ganaderas en el sector referido de la Patagonia.

En principio, el aislamiento se observaba como resultante de dificultades geográficas, la condición de ser áreas lejanas, de difícil acceso y fronterizas administrativamente del centro político, $y$ entendidas como zonas extremas y especiales por tales condiciones. Sin embargo, el año 2007, el Comité Interministerial para el Desarrollo de Zonas Extremas y Especiales (CIDEZE) planteó la necesidad de superar tal enfoque, integrando la idea de "fronteras interiores", a través del concepto de localidades aisladas. Estas fueron definidas como:

"Territorios geográficamente aislados, con bajo nivel de accesibilidad, con escasa población y altamente dispersa, en los que se observa una baja presencia y cobertura de servicios públicos, que como consecuencia de estos factores se encuentran en desventaja y desigualdad respecto del desarrollo del resto del país" (Masalleras \& Ortega, 2012, p. 141).

Al año siguiente, en el 2008, la Subsecretaría de Desarrollo Regional y Administrativa (SUBDERE), siguiendo la propuesta del CIDEZE, tomando como unidad política administrativa de referencia la comuna, actualizó su información respecto a las localidades aisladas, estableciendo conforme a criterios y ponderaciones físicas (10\%), demográficos (15\%), económicos (17\%), acceso a servicios (48\%) y político administrativos (10\%), que un $3,45 \%$ del territorio nacional de Chile se encuentra en condición de aislamiento crítico y que las zonas pobladas, de aislamiento relativamente alto, concentran la no despreciable cifra de un $10 \%$ de la población total del país (SUBDERE, 2008, p. 11).

Estas cifras han refigurado la mirada sobe el territorio e imponen tratos formalmente diferenciados a las denominadas Zonas Extremas y Localidades Aisladas, que tienen condiciones de aislamiento no sólo por el criterio de lejanía respecto a la zona central del país, sino por estar distribuidas en todo el mapa político. Más aún, porque las políticas públicas carecen de flexibilidad, instrumentos adecuados $y$ programas que comprendan los particularismos locales. Con ello, se potencia el análisis de Joel Migdal (2011) sobre el carácter del Estado, que nos acerca a pensar los órdenes sociales como redes de actores y espacios, con creaciones de normas propias y como un conjunto de conflictos larvados, emergentes y litigantes frente a la autoridad, que se pretende imponer piramidalmente como Estado. Asimismo, porque es imprescindible pensar desde una "antropología del Estado" la territorialización, porque una cuestión es la imagen del Estado como institucionalidad superior de obediencia 


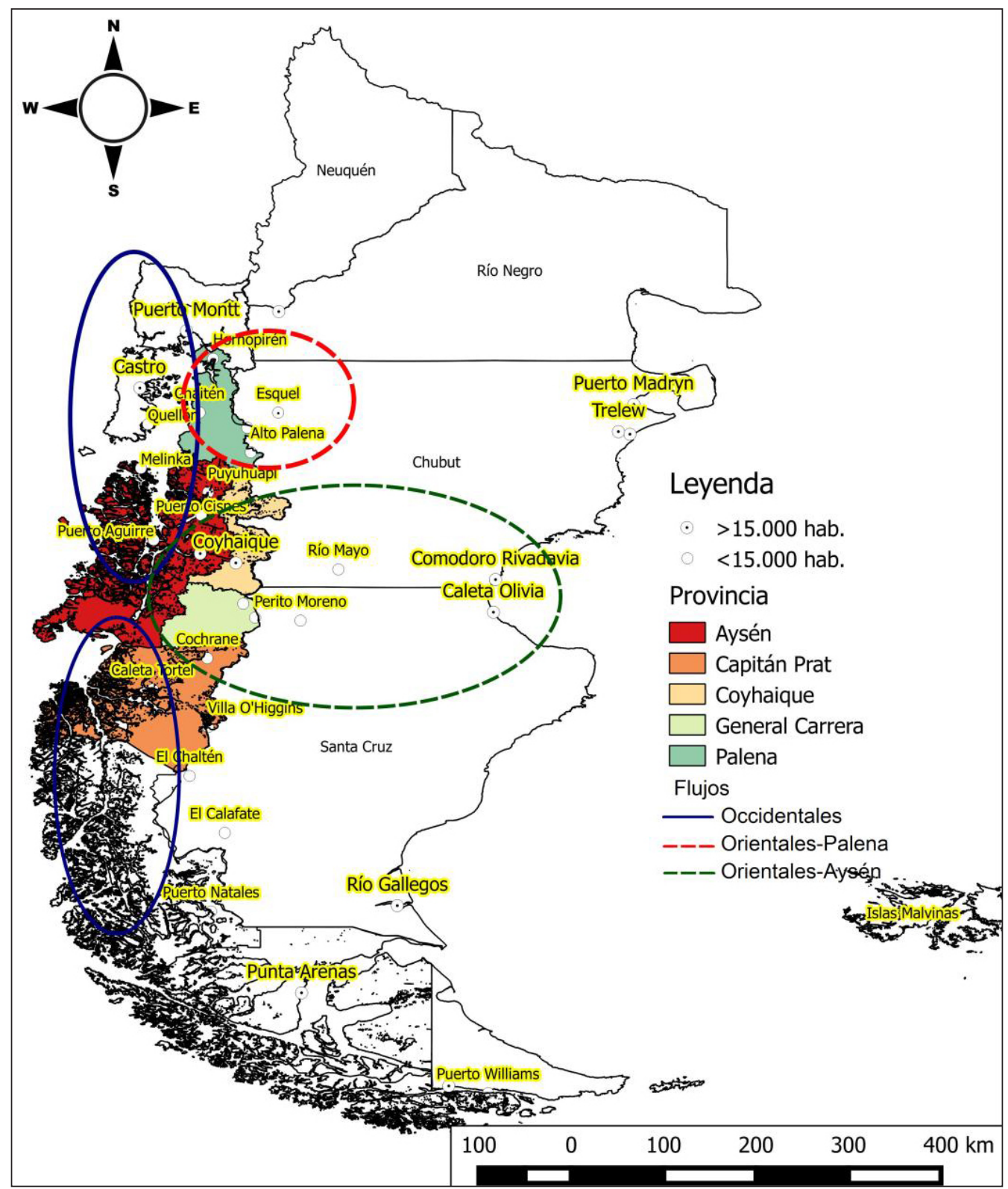

Elaboración: J. Sáenz, 2015

Fig. 2. Flujos de movilida e intercambio en la Patagonia Nor-central.

y protección, y otra, las prácticas del mismo expresadas en el agenciamiento local (op. cit.).

De este modo, se comprende por ejemplo que ciertos sectores rurales patagónicos como $\mathrm{El}$ Diablo, El Tranquilo, El Azul, entre otros, sean aislados respecto al poblado también rural de Alto Palena, el que -fronterizo y con menos de 2.000 habitantes- concentra la oferta de servicios públicos (escuela secundaria y hospital) y comercio, reproduciendo la lógica centro periferia a nivel regional. De ello se desprenden fórmulas como "Plan de Incentivos Especiales para Zonas Extremas" y la "Política Nacional para el Desarrollo de Localidades Aisladas". Esta última se concretó con la promulgación del Decreto Supremo N 608 (2010), cuyos propósitos son: 
1. Materializar el deber del Estado de Chile de promover la integración armónica de todos los sectores de la Nación y asegurar el derecho de todos sus habitantes a participar con igualdad de oportunidades en la vida nacional, independientemente de su lugar de residencia, fomentando la integración plena de aquéllos a la vida nacional; $y$,

2. Promover el liderazgo regional para la gestión de las localidades aisladas, mejorando las condiciones de habitabilidad y coordinando la focalización y flexibilidad de la estrategia para su desarrollo social, cultural y económico.

El ensamblaje territorial se tensiona y define entre lo formal y lo empírico, ya que la Constitución de la República define al Estado como subsidiario, es decir, actúa donde los privados no pueden o no desean invertir. Entonces, cuando ello se despeja y se evalúa al territorio, la presencia agenciada de privados y el Estado es muy diversa, y sus objetivos también muy opuestos; las localidades aisladas para el Estado se presentan como de escasa densidad poblacional, correlacionándose con criterios sobre la rentabilidad de la inversión social, por lo que se debe responder en qué invertir y cuánto. Así, cuando existe poca población, lo mínimo es el máximo, y cada localidad aprende a vivir con decisiones externas que no mejoran la habitabilidad, la inclusión social y la igualdad de oportunidades, por lo que las fronterizas de la Patagonia deben recurrir a servicios argentinos para acceder a alimentos, servicios médicos y recreación.

\section{LA INSULARIDAD DE LA PATAGONIA CHILENA: AUTONOMÍA RELATIVA Y ¿CONSTRUCCIÓN DE UN "PAÍS" APARTE?}

El medio rural del área de influencia de la Carretera Austral, la Patagonia Nor-central chilena (región de Aysén y provincia de Palena), se forjó como un proceso de poblamiento espontáneo, que a comienzos del siglo $\mathrm{XX}$ intenta ocupar el territorio desde el paralelo $42^{\circ}$ hacia el sur, mediante un sistema de concesiones de tierras fiscales, encargando a grandes empresas particulares de explotación ganadera las inversiones $y$ adelantos que permitiesen consolidar los límites del Estado. El compromiso adquirido por tales empresas era la incorporación de más de 1.500 familias de "raza sajona", criterio ya utilizado en la colonización de la Araucanía a fines del siglo anterior, para asentar población e imprimir adelantos en la inmensa extensión (Ibar, 1973; Martinic, 2005). El desconocimiento de las condiciones geográficas, la alta concentración de la tierra, la ausencia de redes de caminos hacia la costa (Puerto Aysén) y fluctuaciones de precios en los mercados de la lana y carne, junto a erróneas estrategias productivas de parte de los inversionistas -que tenían sus casas matrices en Valparaíso $u$ otras ciudades fuera del territorio-, determinaron el abandono de los emprendimientos, de proyectos de mejoras productivas y de conectividad, con la consecuente baja demografía, ya que no hubo fundación y planificación efectiva de asentamientos humanos al privilegiar a trabajadores solteros.

Bascopé (2009) indica que esta estrategia es la que permite adjetivar al territorio en una condición de "desierto". Un desierto que ha sido demográfico por la existencia temprana de mano de obra temporal y la eliminación del cuatrerismo indígena, diluyendo la ganadería pionera; también un desierto biológico, al expulsar a la fauna endémica. Nosotros, además, agregaríamos la idea de desierto alimentario, en la medida que la Patagonia no logró nunca la autosuficiencia alimentaria a través de una política de incentivos o de introducción de tecnología ad hoc, reforzando hasta el día de hoy la dependencia del exterior.

Los múltiples errantes que deambulaban por el paisaje austral (Barros, 1984) comienzan a asentarse dispersamente en un proceso espontáneo de apropiación de tierras excedentarias; primero, en las caras orientales de la cordillera de los Andes -desde las primeras décadas de 1900; luego, hasta la ocupación de áreas occidentales, en la costa y los archipiélagos patagónicos- proceso que se consolida en la década de 1980 (Villagrán et al. 1997; Brinck \& Morales, 2013). Esto último, producto de dos fenómenos: la captura de merluza por parte de pescadores que se desplazaban desde más al norte por el mar interior de Chiloé y el importante desarrollo de la industria del salmón. 
El "éxito" del poblamiento espontáneo de madereros, pescadores artesanales, ganaderos y campesinos frente a las Políticas de Colonización Estatal, devino en un medio rural sin redes administrativas y políticas organizadas, con agenciamientos estatales de baja cobertura profesional (educación, salud, ciencia, tecnología); en un territorio económico, político, social y cultural complejo e inarmónico, separado, de baja frecuencia en las interconexiones y desplazamientos, y en que se aprecia en dos características principales:

a) Una condición demográfica actual de menos de un habitante por kilómetro cuadrado, lo que revela la deficiente política histórica de ocupación en dos siglos de vida republicana; escaso sentido de planificación para fortalecer el arraigo y superar el aislamiento; y, durante décadas, pobre inversión en términos de dotación de servicios territorializados (salud, educación, cultura, recreación, justicia, aeródromos, puertos, vivienda).

b) Ejes de poblamiento diferenciados: un eje occidental de localidades insulares con altos niveles de aislamiento y dinámicas marítimas vinculadas a Chiloé-Puerto Montt en su extremo septentrional, y con la región de Magallanes en su extremo meridional; un eje oriental caracterizado por la concentración del $70 \%$ de la población en las ciudades de Coyhaique y Puerto Aysén, con una periférica población rural que se distribuye de manera dispersa, en localidades con fuerte dinamismo en sus niveles de crecimiento/decrecimiento de acuerdo al diagnóstico realizado en la Estrategia Regional de Desarrollo de Aysén (ILPES, CEPAL \& Gobierno Regional de Aysén, 2009), y donde se presentan flujos transfronterizos que configuran una condición de vida binacional a partir de parentesco político y consanguíneo.

6 Fundamentalmente apuntamos a la dificultad para contar regionalmente con profesionales de excelencia que quieran arraigarse. Y, más aún, cuando se trata de las zonas interiores donde realmente la carencia de profesionales en el área de la educación y la salud es "simplemente dramática" (registro en Lago Verde, 2016). A esta dificultad, debemos agregar
Destacado localmente como un meme el "abandono estatal" sobre la Patagonia 6 , implica una discordancia entre percepción y cifra, ya que el $70 \%$ del PIB regional lo constituye la participación del Estado 7 . Aunque, persiste en los medios rurales más alejados -de los centros urbanos mencionados- la ausencia de vías estructurantes y efectivas de integración nacional, precarias infraestructuras de servicios de salud y educación, y baja presencia de profesionales; forjando modos de vida insulares que constituyen casos particulares de frontera interior. Por ejemplo, desde Villa O'Higgins a Caleta Tortel hay 150 km. de distancia; a Cochrane 230 km; a Chaltén Argentina, 110 km, cruzando Lago O'Higgins y Laguna del Desierto; y, a Coyhaique, la capital regional, $530 \mathrm{kms}$., lo que no es traducible en horas de viaje por kilómetro recorrido.

En la comuna continental de Puerto Ibáñez, un ganadero entrevistado (2015) percibía que vivir en la región de Aysén es vivir en una isla: esto es una isla. Llegas por mar o por avión, o usas las carreteras de Argentina. En paralelo, la Estrategia Regional de Desarrollo de Aysén señala la misma idea: no en vano, los habitantes de Aysén suelen describir la región como una isla: al oeste limita con el mar, al este con Argentina, al sur con los campos de hielo y al norte evidencia una marcada discontinuidad vial terrestre (2009, p. 33). Una mujer entrevistada en Puyuhuapi (2015), señalaba: termina febrero, y quedamos mirándonos unos a otros hasta diciembre... no viene nadie y no hay nada que hacer. Mientras, una profesora soltera proveniente de la ciudad de Valparaíso, trabajando en una localidad limítrofe de menos de 200 habitantes, señala que: la ruralidad te atrapa... es tanta la distancia [tiempo] para ir a Coyhaique, que a veces no te dan ganas de ir a comprar... pero acá no hay nada. Si no encuentras pareja, la vida se hace muy dura... muy dura. Es un mundo desconectado, por eso no duran los profesionales. No basta la belleza del paisaje.

que en las comunas de Lago Verde, Cisnes, Guaitecas, O`Higgins, Tortel y Río Ibáñez no existen farmacias (MINSAL, 2015, p. 22).

7 Nos referimos al peso que tiene el empleo público, las asignaciones de zona y la construcción de tramos de la Carretera Austral (Ruta G7). 
VIDA COTIDIANA DE LAS UNIDADES DOMÉSTICAS: EJE OCCIDENTAL Y ORIENTAL

La auto-percepción de vivir en la frontera de la exclusión se manifiesta en reconocerse permanentemente como otros dentro del Estado nación unitario, identificando a Chile como el espacio "del norte" y de concentración de poder y oportunidades; el que sería "una suerte de país aparte, que llega hasta Puerto Montt" -señalan distintos entrevistados en Futaleufú-, lo que se expresa en el habla asociada al viaje en un "ir a Chile" o "voy a Chile". Para muchas localidades alejadas el único aeropuerto que funciona todo el año está en Balmaceda. "Ir a Chile" la mayoría de las veces es hacerlo por Argentina, vía ruta 40; para otras comunas como Villa O'Higgins, Chile Chico, Lago Verde, Palena y Futaleufú la interacción con localidades argentinas es la rutina cotidiana. Estas últimas localidades por lejanía de los centros urbanos más importantes, o lejanía de la propia Carretera Austral- constituyen islas dentro de la misma Patagonia. En esas zonas se destacan redes familiares o clanes binacionales como los Solís, los Oyarzo y los Jaramillo en Lago Verde, La Tapera y Villa Amengual (Coyhaique) con Villa Las Palmas (Chubut) (Álvarez, 2012; Núñez et al. 2017). Éste concepto de "islas" refuerza la mencionada analogía de la Patagonia como un archipiélago, continental y oceánico.

Al mismo tiempo, en la experiencia de vida se asienta un carácter patriótico existencial, pues "vivir aquî", en "la periferia de Chile", también se percibe como hacer patria en la frontera. Esto último, por una parte revela la lógica de la escuela nacional, la presencia de carabineros y el ejército como instituciones emblemáticas de divulgación de la identidad nacional se transforma en una disputa simbólica entre la "cultura huasa" o "campesina" importada del centro del país y la "gaucha" o ganadera de carácter binacional; $y$, por otra, que el hacer soberanía, es decir, permanecer o habitar localmente pese a las limitaciones objetivas, se transforme en una cuestión clientelar, con demandas específicas de subsidios diversos a la administración central del Estado a través de los

8 La situación se agudiza al interior de la región de Aysén, ya que los trayectos a Coyhaique son in extremo difíciles o imposibles con lluvia. Por eso, una profesora en Lago municipios, más que en la exigencia de políticas públicas focalizadas que impliquen procesos de racionalización política administrativa.

Sin embargo, la percepción de aislamiento es relativa y matizada, acentuándose más en la población urbana que rural (Arenas et al. 2011) que la tiene más naturalizada, ya que en la ciudad (Coyhaique y Aysén) es donde más se consume y buscan modos más diferenciados de presentar la identidad, la autoexpresión y la secularización, cuestión que no elimina la crítica a las pocas posibilidades de "hacer cosas". Esta afirmación se sustenta en información arrojada por la encuesta a estudiantes de 4to. Medio mencionada, la que muestra que el $52,3 \%$ de ellos declara que no les gusta el aislamiento, la desconexión y falta de acceso a bienes y entretención, y echan de menos las disponibles en las ciudades importantes del Chile central. En Aysén interior, donde existen menos elementos de contraste, los recursos y bienes culturales disminuyen dramáticamente, aunque no el deseo de migrar. En las comunas de Palena y Futaleufú, los espejos son las ciudades argentinas como Esquel y Bariloche.

En tanto, en las zonas rurales se han fraguado estrategias y respuestas locales para sobrellevar las insuficiencias y el precario acceso a servicios que demanda la existencia cotidiana. Por ejemplo, en Villa O'Higgins, aledaña a los Campos de hielo Sur, en el plano de la salud un habitante entrevistado en el año 2014, identifica dos tipos de enfermedades: las no graves, que se pueden mejorar localmente [en la casa]; $y$, las otras que te matan [que requieren atención especializada]. Esta sentencia es el reflejo de sus cerca de 400 habitantes, los que cuando deben y pueden movilizarse, demoran hasta dos días para llegar al Hospital Regional de Coyhaique, porque en la Patagonia los imprevistos son parte de la vida y nada es seguro en estos caminos (en Villa O'Higgins, 2014).

En general, para sobrellevar las insuficiencias en servicios médicos, escaso mercado laboral y el encarecimiento del costo de la vida en los insumos básicos para el hogar, se han gestado flujos históricos de movilidad e intercambio binacionales (Fig. 2), con ciudades argentinas mejor dotadas

Verde señala: aquí se vive sin libros, sin diarios y con mucho alcohol. 
de infraestructura de servicios e incluso acceso gratuito en salud y educación ${ }^{9}$. En particular, la circulación de la población de la provincia de Palena ha configurado un área transfronteriza cuyo núcleo es la ciudad de Esquel, ubicada en la provincia del Chubut (Argentina), mientras que en la región de Aysén, el flujo histórico ha constituido un área transfronteriza de circulación mucho más amplia, que incluye Comodoro Rivadavia en el litoral chubutense y Perito Moreno, en la provincia de Santa Cruz, más cercana para la población austral aysenina, desde el paralelo $46^{\circ}$ al sur.

Las comunas más rurales no sólo muestran una dificultad mayor para retener y arraigar población (Mandujano \& Rodríguez, 2016, p. 75) sino que también para arraigar capital humano: una autoridad comunal en Lago Verde (2016) relata que en muchos de los concursos públicos para llenar cargos, se termina contratando al "único postulante". Pero, además, una vez asignado el cargo, hay una entropía perversa derivada del aislamiento: la falta de perfeccionamiento y de contacto con otros profesionales que tiende a deteriorar estándares esperados para cumplir el rol. Esto lo reflejan las palabras de un maestro de escuela rural que en la entrevista nos cuenta que: si uno se descuida, el campo lo atrapa a uno (en Ñirehuao, 2013). Al parecer el ejercicio profesional en territorios no sólo desprovistos de recursos materiales y económicos, sino especialmente dotados de una comunidad de pares y demográficamente pequeña, dispersa y con bajos niveles de escolaridad, impone costos personales, profesionales y comunitarios que son difíciles de revertir, y que normalmente aumentan la brecha entre el deber ser de los desempeños que se esperan en empleos financiados con recursos fiscales y el rendimiento real de autoridades, profesionales $y$

9 El régimen de tipo Federal, permite administrar recursos y fijar prioridades locales, aún cuando la población pueda quejarse del peso estratégico que posee Buenos Aires en términos de acaparamiento de recursos, bienes $y$ oportunidades.

10 El concepto incluye una diversidad de agentes y actores: campesinos, pequeños y medianos productores, medieros, productores sin tierra, parceleros, entre otros, que realizan distintas actividades agrícolas, forestales, ganaderas o pesqueras, cuya particularidad no recae sólo en sus formas de organizar la producción, sino como "modos de vida", ya que el fin último es la reproducción social de la familia "en condiciones dignas" (Craviotti, 2014). empleados, en desmedro de las condiciones de vida de la zona.

Por otra parte, los emprendimientos de minifundios y parcelas familiares tan frecuentes en otras latitudes del país, incluso al frente del golfo Corcovado en las islas de Chiloé, que son unidades domésticas llamadas Agricultura Familiar Campesina o AFC (FAO, 2014) ${ }^{10}$, muestran baja homogeneidad $y$ un equilibrio precario permanente. Esto, porque las unidades políticas administrativas por sus tamaños y alta dispersión de unidades familiares campesinas, en los lugares donde existe alguna concentración demográfica no cuentan con mercados de escala y con alternativas, lo que dificulta la producción y distribución, asî como la circulación de bienes y posibilidades de diversificación del consumo ${ }^{11}$. Asimismo, en los municipios rurales y alejados de Coyhaique y Aysén, se reconoce que se produce la prevalencia de un "alto uso de licencias médicas" por parte de profesionales, "especialmente profesores" (en Lago Verde, 2016). Cuestión cuyo genérico sería "la depresión", lo que estaría marcada por "la soledad y el aislamiento", y porque "no hay cómo tratar las enfermedades".

En el eje oriental, debido a condiciones climáticas extremas, con una oscilación térmica que entre invierno y verano supera los $30^{\circ}$ celsius, y la pobreza de suelos producto de la ovejería extensiva, la producción agrícola se restringe a puntuales localidades cercanas al límite con Argentina, que cuentan con favorables condiciones microclimáticas, como es el caso de Chile Chico, separada artificialmente de Los Antiguos (Argentina). Por esta razón, en la mayor parte del territorio predomina el rubro pecuario, y en segundo lugar el forestal ${ }^{12}$. Los principales problemas productivos para las AFC de este amplio espacio son la escasa

11 La distancia de las localidades interiores con el puerto de Chacabuco, los costos de transporte y la ausencia de plantas faenadoras de carne locales, son una seria limitante para generar una productividad superior. Por otro lado, el que la tierra esté sometida a un régimen de "tierras protegidas" por parte del Estado, impide un uso extensivo de talaje para los animales, lo que define un umbral y magnitud posible de animales de las AFC.

12 Información disponible en la página web de CIREN: http://comercial.ciren.cl/index.php?option =com k2\&view=item\&layout=item\&id=91 Revisado en septiembre, 2015. 
diversificación, la estacionalidad, la vulnerabilidad productiva (sequía o inviernos blancos), la lejanía de mercados para negociar sus productos y la falta de infraestructuras que permitan integrar a los diversos agentes a un circuito agroalimentario mayor. Una de las demandas históricas del sector agropecuario al mundo público, al Estado diremos, ha sido la construcción de plantas faenadoras y frigoríficas certificadas que permitan la exportación de la carne con denominación de origen. Una planta faenadora ovina, finalmente la ha implementado de manera privada la mayor estancia de Aysén, y de Chile, propiedad de una familia belga-estadounidense, lo que ratifica el escaso agenciamiento del Estado y la política pública para permitir la existencia de estos modos de vida, potenciar lo que es la actividad más tradicional y generar arraigos, ya que -dadas las magnitudes de población- "invertir es percibido como un gasto", indica un ganadero del tipo AFC, en Río Ibáñez.

Conforme a lo anterior, es posible sostener que el rubro pecuario no ha cambiado sustancialmente desde la colonización, cuando se desplazaban los rebaños por grandes distancias para su venta, pudiendo involucrar hasta dos meses de viajes para obtener alrededor de $13 \%$ de utilidades anuales, situación favorable que ocurría en el $1 \%$ de los productores (Chonchol, 1952). La única diferencia es que en los años que escribía Jacques Chonchol, la venta de la producción de lana permitía a cada unidad familiar abastecerse anualmente. En la actualidad, aunque las posibilidades de desplazamiento o exportación son mayores, el precio de la lana ya no tiene su antiguo valor, ni es fundamental como especialización productiva; exceptuando la comuna de Cochrane que mediante el acopio colectivo (AG Río Baker) ha logrado prescindir de intermediarios para comercializar lana a mercados uruguayos, europeos y asiáticos ${ }^{13}$, consiguiendo "un precio razonable" -señala un productor entrevistado en el año 2015. La situación no se observa en el resto del territorio; el valor de la lana puede ser tan bajo -como pudimos registrar en la provincia de Palena- que incluso la esquila resulta más cara que las utilidades (Sáenz, 2015).

13 Información y datos disponibles en la página web de la Asociación Gremial Río Baker: http://www.ag-riobaker.cl/
Por esta razón, muchas AFC privilegian la producción bovina, en particular como crianceros o criadores de terneros/as, en un sistema productivo extensivo de baja carga animal por hectárea, que requiere al menos 15 meses para la venta del producto. Posterior a 7 meses de la cría, en el caso de Aysén, las AFC deben trasladar los terneros/as a las ferias regionales de Coyhaique y de La Junta; y en el caso de la provincia de Palena, a las distantes ferias de Puerto Montt y también de La Junta. En ambos casos, las localidades de venta son extra-provinciales, por lo que las distancias -igual que en la década del 50 y 60 (CORFO, $1950,1960)$ incrementan los costos y riesgos de pérdidas en el transporte y el peso de los animales, por lo que muchos optan por vender localmente a través de intermediarios.

Lo importante en esta ruralidad (AFC orientales) son los efectos en el plano de la reproducción de las unidades familiares y económicas. En primer lugar, por la estructura de comercialización y las limitaciones y normativas para el uso del ecosistema (parques nacionales y privados, reservas nacionales), las unidades se deben organizar para vivir con ingresos percibidos cada 15 meses; y, en segundo lugar, que la capacidad de reproducción social y de arraigo de las unidades domésticas se ve amenazada en localidades que no cuentan con oferta educativa para sus hijos/as, una vez superado el nivel básico. Esto se ve acrecentado en caso de optar por estudios superiores, porque la decisión puede implicar la migración inter-regional hacia ciudades de la zona central del país, con incierto retorno. Tales condiciones refuerzan el aislamiento, favorecen un envejecimiento poblacional, el debilitamiento de la cultura laboral, la pérdida de fuerza de trabajo y estimulan procesos migratorios que justamente Son rasgos que identifican la ruralidad patagónica; lo que tiene impacto en la decisión de trasladar a sus hijos a centros urbanos con mayor dotación de servicios, fragmentar la unidad familiar, duplicar gastos al mantener una vivienda en el campo asociada a la actividad productiva y otra en la ciudad para satisfacer demandas asociadas a imaginarios urbanos y de consumo.

web/index.php Recuperada en septiembre, 2015. 
En el eje occidental, la cobertura en salud y educación es más precaria. En cuatro de las 14 comunas del área estudiada, no existen liceos, o los que hay "no garantizan una educación con perspectivas", por lo que gran parte de las familias debe pensar en el traslado de sus hijos a Aysén y Coyhaique $^{14}$, aunque en el caso de la comuna de Las Guaitecas la mayoría de los niños estudian en la X Región, debido a su cercanía ${ }^{15}$. Para problemas urgentes de salud, hay que trasladarse a los lejanos centros continentales, mientras que las posibilidades de control médico se restringen a la frecuente irregularidad del transporte aéreo o marítimo, siempre condicionado por el estado del clima. En el litoral, esta situación incluye los problemas asociados al control que efectúa el Servicio Médico Legal, pues ante el fallecimiento de una persona, es obligación enviar especialistas desde Aysén, restringidos también por condiciones climáticas que no siempre permiten el desplazamiento expedito. Esto hace que la angustia y el dolor "se alargue" (en Guaitecas, 2015).

A diferencia del eje oriental, el poblamiento del litoral presenta una dispersión más nuclear, distribuida en pequeñas localidades con fuertes vínculos comunitarios. Aquí, las actividades agropecuarias no son predominantes debido a la inexistencia de infraestructuras de conectividad que hagan rentable el traslado de estos productos hacia mercados del norte, siendo destinados principalmente al autoconsumo y el pequeño mercado local. Las AFC tradicionales están más vinculadas a la extracción de recursos bentónicos, y desde 1985, a la pesca demersal de carácter artesanal (Saavedra, 2007). El subsector "pesca artesanal" reúne más de 3.000 pescadores y 115 organizaciones, entre asociaciones gremiales, cooperativas, sindicatos y Sociedades de Responsabilidad Limitada (SERNAPESCA, 2015).

Los ritmos productivos también difieren en el litoral. Las actividades y decisiones no están determinadas sólo por ciclos naturales como

14 El 7 de agosto del año 2015, se promulga la ley 20.842, que crea la Universidad de Aysén.

15 Las localidades que más población pierden, son aquellas que no poseen educación secundaria, lo que se ha agudizado con la construcción de la Ruta G7 (Carretera Austral), la que ha aumentado el flujo migratorio intrarregional con destino a Coyhaique, la capital regional. En el caso de la ocurre en el sistema agropecuario extensivo, sino que paralelamente inciden decisiones climáticas y gubernamentales como en el caso de la captura de la merluza y otros recursos demersales, cuya actividad se realiza bajo el control administrativo de la Subsecretaría de Pesca. Ésta fija vedas y cuotas globales de captura, las que son repartidas entre el sector artesanal $e$ industrial, y que se realizan en dos o tres días al mes, mediante un calendario de autorización. Otra limitante para su desarrollo está asociada a la llamada "marea roja", un fenómeno natural (e histórico) consistente en el aumento del número de micro-algas en el agua, que son parte de la cadena alimentaria de los moluscos filtradores. Éstos se contaminan y sus efectos tóxicos son traspasados a los humanos, por lo que su extracción queda prohibida por la autoridad y la población especializada debe buscar otras fuentes de ingreso, y esperar subsidios o ayuda de parte del Estado para la sobrevivencia, porque no existen otras fuentes laborales.

La figura del Estado es invocada en su carácter protector, aunque revelando todo el déficit de su práctica territorializada, reforzándose la idea de lejanía y frontera interior. Como vemos, varias cuestiones complejizan la condición de la ruralidad patagónica de la provincia de Palena y la región de Aysén. Por una parte, hay una interpelación al Estado; por otra, los costos productivos son altos por las distancias y por la falta de vías estructurantes de conectividad, existiendo una dependencia extra-regional de todos aquellos insumos que no son producidos localmente, los que llegan por camiones, en barcazas, o por Argentina, desde el centro sur. En estos términos, la dispersión y fragmentación territorial revela que a diferencia de los espacios exclusivamente rurales (predios agropecuarios distribuidos en localidades), en los centros poblados (pueblos, villas y aldeas) no existe autosuficiencia alimentaria, por lo que en un desierto alimentario siempre se es dependiente del exterior. Además, persiste una administración

isla Melinka, en el Municipio de Guaitecas, a 83 kilómetros lineales de Quellón por el mar interior, en Chiloé Insular; o, a 220 de Coyhaique, recién en el año 2016 se cuenta con educación media completa en el Liceo. Esto es importante para familias que no tenían cómo financiar educación en otros lugares. 
a distancia que remarca el carácter centralista de las políticas públicas, las que no reconocen los particularismos del heterogéneo territorio de la Patagonia, planificando y fiscalizando con indicadores de carácter nacional en la fijación de salarios, costo de vida, programas y calendarios escolares.

\section{SOBREVIVENCIA, ESTRATEGIAS ALTERNATIVAS Y ACUMULACIÓN}

Las AFC locales han desarrollado estrategias productivas y sociales resilientes para sobrellevar las condiciones adversas señaladas. A nivel productivo, fue posible registrar la mantención de estrategias de vida o medios de supervivencia simultáneos con las estrategias de acumulación, propias de racionalidades de pequeños o medianos empresarios agrícolas en que la producción se organiza orientada al mercado (véase también Mora-Delgado, 2008). Las AFC patagónicas son capaces aun de restringir la comercialización de sus productos cuando el precio del mercado es muy bajo, aspecto observado entre 2013-2014 en localidades aisladas de la provincia de Palena (Sáenz, 2015), lo que confirma que también sus actividades son orientadas a imprimir mejoras en su hogar antes que a la pura rentabilidad, similar a la lógica del campesinado clásico caracterizado por E. Wolf (1971). En general, es posible sostener que las AFC favorecen en primer lugar su propio auto-sustento y reproducción social, y sólo posteriormente el comercio, transformando muchas veces sus excedentes en fondos de reemplazo y/o ceremonial (Wolf, op. cit.), aumentando su masa ganadera que será vendida en cuanto suba el precio por la demanda, lo que implica a veces esperar la próxima temporada anual.

A pesar de estas adversidades, se percibe a través del trabajo de campo que -en perspectiva histórica- es posible vivir con incluso "más desventajas": "antes no había caminos", "antes

16 Una cuestión importante para esta contracción de posibilidades estaría dada por el proyecto de D. Tompkins para la construcción de grandes bio-corredores para que la flora y fauna estén libres de acción antrópica. Primero, entregar al Estado el parque privado Pumalín, de 293.000 ha, a las que se sumarían 109.392 aportadas por el Estado a través de la Corporación Nacional Forestal (CONAF), dando nevaba más", "nuestra crianza fue muy dura", "antes no comprábamos ropa", "estuvimos vestidos a pura lana... pero comida, nunca faltó", señalan los entrevistados en Cochrane en 2014-2015. Porque en el pasado, se confirma había mayor producción, mayor cantidad de tierras disponibles, capacidad de carga superior de los ecosistemas y menos agentes externos que impidan el uso del bosque y los pastizales ${ }^{16}$; por ello, se insiste en entrevistas en el mismo lugar: lo que más había era comida y no se notaba el costo, porque era la producción de uno. Tales lecciones se mantienen en el imaginario rural, y que se revela en la lógica de un ganadero: no vendi animales el año 2014, pese a un buen precio. No sería justo que después tuviera que comprar carne. Si se aprecia, se favorece el autoconsumo antes que el comercio.

Junto a lo anterior, además se debe considerar que la misma condición de frontera interior permite el acceso gratuito a los atributos naturales de la bioregión patagónica, entendida ésta como una unidad relativamente grande de tierra o agua, como un conglomerado geográfico en el que se identifican especies, comunidades naturales y condiciones ambientales. Paradójicamente, la condición de frontera interior es la que esconde los recursos a los que el capital no puede acceder por la misma falta de vías de conectividad. Así, entre otras ventajas, aún las AFC gozan de irrestricta autonomía hídrica, puesto que cada predio cuenta con arroyos o lagunas que proveen de agua al hogar como a la producción. Y en el caso del litoral, el control y la deficitaria fiscalización por el costo económico que significa para el Estado neoliberal la "dotación de personal" de sus instituciones, también permiten la extracción de recursos marinos sujetos a veda y que contribuyen a la dieta y reproducción biológica de la unidad familiar.

No obstante lo anterior, la autonomía descrita es relativa y sumamente frágil. La capacidad actual de carga de los ecosistemas es limitada y demanda entre 4-5 hectáreas

origen a un megaparque nacional; segundo, la formación del gran Parque Nacional Patagonia, que ambicionaba unir la propiedad de su fundación de 83.723 ha y 220.804 ha del Estado. Ambas iniciativas se concretaron en abril de 2019, con lo que los parques nacionales del sur, con 17 áreas de vida silvestre, sumaron 11.8 millones de hectáreas. 
por vacuno. Con ello, la propiedad de 500 hectáreas de tierra puede poner a los pequeños productores al límite de la subsistencia, aunque desde la institucionalidad puede ser leído como un "gran capital". Esto ha contribuido a intensificar estrategias extra-prediales (cuidadores de parcelas, constructores, carpinteros, boteros, transportistas, entre otras) para la obtención de ingresos y estabilización de las unidades familiares, fenómeno que se formaliza conceptual y analíticamente como nueva ruralidad latinoamericana con la caracterización de pluriactividad campesinacomo se ha indicado más arriba (Salas et al. 2011), y el establecimiento de Parques Nacionales y Reservas Nacionales, distintas legislaciones y códigos vigentes, y por la entrada de nuevos actores al mercado de tierras que imponen limitaciones de uso a través de compra de grandes extensiones, con objetivos filantrópicos (ecología profunda), especulativos o de rentabilidad a través de parcelaciones y venta de bonos de carbono (véase Rodríguez et al. 2016).

Las estrategias de sobrevivencia de las unidades económicas y domésticas rurales, de mano de la pluri-actividad, se han traducido en las altas tasas de migración interna e inter-regional, pero sobre todo en los repentinos cambios poblacionales que existen en las localidades rurales interiores en los últimos 50 años. Se trata de una movilidad circular, de ida y vuelta; y una migración internacional mutua, pero con redes transnacionales.

Los cambios demográficos y territoriales más fundamentales están asociados a faenas de tipo litoral, ligadas a la industria del salmón. Son unas 5.500 personas empleadas en la región en esta industria, de las cuales el $70 \%$ viene de otras regiones, generando muchos de ellos el proceso económico de la conmutación (recibir en un lugar y gastar en otro), aunque presionando las condiciones de habitabilidad conforme a la capacidad de carga local (vivienda, alimentos, servicios). Pero, también, la amplitud de las concesiones de una industria de gran expansión y convertida en un clusters, tiene un conjunto de observaciones que son contradicciones

17 Espacio marino-costero, referido a un área geográfica o magnitud de mar, en el que se expresa un lenguaje del océano, los oficios, las prácticas, los significados y los valores conferidos por la comunidad, para usar, acceder, propias del modelo: 1) acaparamiento de concesiones; 2) correr los límites de los parques marítimos para favorecer la expansión hasta una superficie de 1.915.000 hectáreas aptas para la acuicultura (AAA); 3) afectación de zonas de desarrollo turístico con características premium como entornos escénicos; 4) contradicciones con las unidades pesqueras artesanales, en competencia con sus fondeaderos históricos y lugares propios para la actividad extractiva; 5) contaminación de aguas producto de sobrecarga de peces, generando hipoxia (bajo nivel de oxígeno) y anoxia (sin oxígeno) (Aguilera, 2015). Finalmente, en la zona costera se constituye una red de caminos de agua, superiores en intensidad a los terrestres. Los de agua son de ejecución rápida y están conectados con el mundo, los terrestres son de grandes inversiones y está en disputa a dónde conducirán.

\section{COMENTARIOS FINALES}

Palena y Aysén, en la Patagonia Nor-central, son algunos de los últimos territorios en incorporarse a la República chilena en su construcción estatal desde la perspectiva de los servicios territorializados. Esto significa reconocer la existencia de un gran espacio austral concebido como fronterizo e inexplorado en las zonas interiores en el siglo XXI. Tales características que podrían pensarse como pasadas, se han revelado persistentes al trabajo etnográfico, a propósito de costos involucrados para la construcción de vías, la conectividad interior y dificultades de integración policéntrica. Se trata de condicionantes que configuran una bio-región, aunque en las zonas costeras con la actividad de la industria del salmón pueden identificarse puntos globalizados, los que litigan sobre espacios asociados a actividades pesqueras artesanales que por definición son nómades. En este sentido, el maritorio ${ }^{17}$ está en construcción y transformación por la actividad artesanal, la industria del salmón y la pesca de arrastre.

Constituido el territorio como frontera, las diversas políticas públicas junto al desplazamiento de fuerzas globales que tienden a controlar fuentes

administrar y proyectar el carácter de su cultura. La apropiación específica, refleja los rasgos identitarios, los modos de vida y la cosmovisión presentes en el territorio cultural. 
de recursos (agua, energía, paisajes, ecosistemas, madera, estuarios), dan pie a una Nueva Ruralidad con rasgos propios, escindida del tránsito hacia lo agroindustrial y urbano que caracteriza al proceso en otros países latinoamericanos. Al contrario, el problema rural patagónico chileno se presenta más bien como una fragilización de la vida, en creciente disputa por el control territorial con formas de enclave, donde se enfrentan lógicas de apropiación espacial campesinas - ganaderas frente a modelos incompatibles de acumulación de capital, sean extractivistas, de conservación ecológica, o de turismo de intereses especiales. Las unidades familiares campesinas especializadas en ganadería requieren de amplios ecosistemas para ser sustentables, para ubicarse sobre umbrales mayores a los de la subsistencia y que permitan la retención como posibilidad de vida local, pero se ven limitados por ordenanzas legales, tierras privadas cercadas y con propietarios ausentes, filosofías restaurativas como la ecología profunda que expulsan fauna exógena y clausuran posibilidades reproductivas, e intereses energéticos extra-territoriales que pretenden controlar recursos regionales.

Lo significativo en este proceso, es que pese a las diversas Políticas de Colonización, ha sido la población rural -resultante de un proceso de poblamiento espontáneo- la que mayor nivel de arraigo y tiempo efectivo de residencia ha demostrado en los últimos cien años. Sin embargo, las demandas de la población rural tradicional, ligadas a mayor cobertura de servicios y conectividad, las aspiraciones al consumo entre los más jóvenes, y sobre todo políticas que favorezcan su incorporación a los circuitos agroalimentarios mundiales a través de sellos con denominación de origen, han sido desestimadas o en el mejor de los casos, convertidas en programas públicos de alto costo que no han podido sostenerse en el tiempo. Aquí, debe reconocerse una limitación constitucional: no se consagra el derecho a permanecer localizadamente como cultura del trabajo, que es un modo de protección subsidiado del Estado hacia el habitar rural, como acontece en zonas de la Comunidad Económica Europea.

La población rural patagónica incorporada al Estado chileno como "agente de avanzada", cuyo rol fundamental era garantizar la soberanía de límites fronterizos, se encuentra en la actualidad en una situación indefinida. Muy separadas e independientes las unidades productivas, con diferencias sustantivas unas de otras, donde también el valor patriótico de su existencia ha decrecido considerablemente frente a las nuevas posibilidades que ofrece el capitalismo deslocalizado; también, junto a la reciente revalorización de paisajes prístinos que incluyen la producción simbólica de elementos y valores vinculados al ecologismo (Ecología Profunda), propuestas restaurativas de ecosistemas y lo verde como commodity, que circulan como narrativa posmaterialista en las grandes urbes globales. Así, la Patagonia se ha convertido en una marca territorial globalizada capaz de activar imaginarios que excluyen muchas veces las culturas locales, construida bajo el eslogan: "reserva de vida".

En este proceso de agenciamiento es interesante abordar etnográficamente el arraigo que da continuidad a la población rural tradicional, pues superando la perspectiva centralista, descubrimos que a diferencia de la concentración propia de los centros urbanos, la dispersión geográfica de las AFC corresponde a una territorialidad compleja para responder en cierta medida a las condiciones de desventaja dadas por el aislamiento. Esto, porque incluye una serie de estrategias, prácticas e imaginarios socio-espaciales que junto con ser productivos, organizan la vida y permiten la reproducción social, que es el fin último de las unidades domésticas.

$\mathrm{Si}$ a las ya tradicionales prácticas de explotación agropecuaria extensiva y de pesca artesanal se agregaron dinámicas de intercambio y flujos de movilidad entre localidades con alcance binacional, como parte de las estrategias para acceder a servicios ausentes en Chile, hoy ante el avance vertical de las fuerzas globales resulta inquietante observar nuevos procesos de localización y relocalización, es decir, procesos de reacción y reinvención local. Éstos se encuentran caracterizados -entre otros- por la formación de un mercado de tierras rurales que se incorpora como una lucrativa estrategia de vida local, pero cuyo revés está significando la des-agrarización progresiva de los espacios rurales. Muchos pobladores confirmaron en entrevistas la idea de que es mucho más rentable vender sus predios 
como suelo, para otros fines de tipo especulativo, inmobiliario, turístico o de conservación, que incluso si vendiesen todos sus animales. La desagrarización moviliza personas y permite la emergencia de nuevos sujetos rurales, como los cuidadores de propiedades de extranjeros, los carpinteros de los múltiples lodges turísticos o campesinos trasplantados en áreas urbanas vulnerables.

Las formaciones globales movilizan imaginarios verdes que revalorizan el aislamiento. Dado el mayor poder adquisitivo y tecnológico que poseen sus actores (objetos para deportes, vehículos especializados, vestuario), incluso han permitido soslayar los problemas de conectividad y conexión con infraestructuras dotadas con servicios de internet, luz eléctrica e incluso personal médico privado, cuyas restricciones son consideradas privilegios para sostener la intimidad y anonimato, utilizando helicópteros para su acceso. De aquí, resulta importante cuestionarse nuevamente por la condición de frontera interior; planteado así, ya no es un problema geográfico el determinante, sino de distribución y acceso a servicios en el segmento de la población rural aislada por parte del Estado. La diferencia más significativa con los actores globales, es su capacidad de habitar el territorio continuamente, incluso en el invierno más crudo, bajo la percepción de una naturaleza imprevisible, pues los afuerinos o neocolonos mantienen un arraigo limitado a ser propietarios con gestión deslocalizada. Por esta razón, es que el fantasma del despoblamiento futuro del territorio austral puede leerse con valores opuestos según sea campesino, maderero, gaucho, pescador artesanal o nuevo colono.

\section{AGRADECIMIENTOS}

Este trabajo es producto del Proyecto Fondecyt 1161013 "De los ensamblajes locales, regionales y nacionales a los ensamblajes globales. Etnografía y política de las relaciones de sujeción local en el área de influencia de la Carretera Austral, la provincia de Palena y la región de Aysén”.

\section{BIBLIOGRAFÍA}

Aguilera, M. (2015). Aysén y la salmonicultura. https:// www.eldivisadero.cl/redac-33458. Consultado 13 de noviembre de 2016.

Álvarez San Martin, M. (2012). Historias de Aysén: vida y costumbres de un pueblo reciente. Tesis de Grado, Universidad de Chile.

Anderson, B. (2006). Las comunidades imaginadas. Reflexiones sobre el origen y la difusión del nacionalismo. FCE, México, D.F.

Arenas, F., Salazar, A., \& Núñez, A. (Eds.) (2011). El aislamiento geográfico: ¿problema u oportunidad? Experiencias, interpretaciones y políticas públicas. Serie Geolibros №15. Santiago de Chile: Instituto de Geografía, Pontificia Universidad Católica de Chile,.

Barkin, D. (2001). La nueva ruralidad y la globalización. En E. Pérez, A. Farah \& H. Carton (Comps.), La nueva ruralidad en América Latina, Tomo II (pp. 21-40). Bogotá: Pontificia Universidad Javeriana.

Barros, M. (1984). Palena: un río, un arbitraje. Santiago de Chile: Editorial Santillana.

Bascope, J. (2009) De la exploración a la explotación. Tres notas sobre la colonización de la Patagonia austral. Disponible en: https://nuevomundo.revues.org/56645

Bonnal, P., Bosc, P., Díaz, M., \& Losch, B. (2004). Multifuncionalidad de la agricultura y nueva ruralidad: ¿reestructuración de las políticas públicas a la hora de la globalización?, en E. Pérez \& A. Farah (Comps.), Desarrollo rural y nueva ruralidad en América Latina y la Unión Europea (pp. 19-41). Bogotá: Pontificia Universidad Javeriana.

Brinck, G., \& Morales. C. (2013). De la Movilidad a la Sedentarización. Historia y territorio entre los pescadores de Puerto Gala, Región de Aysén. Revista Márgenes de la Universidad de Valparaíso, 10 (12), 37-51

Carton de Grammont, H. (1999). Agricultura de exportación en tiempos de globalización. México: Juan Pablos Editor.

Carton de Grammont \& L. Martínez (2009). La pluriactividad en el campo latinoamericano. Quito: Facultad de Ciencias Sociales.

CIDEZE (2007). Política Pública para Territorios Especiales Aislados (Documento Base). Disponible en: http:// www.subdere.cl/1510/articles-67660_recurso_2.pdf Revisado en mayo, 2013.

CIREN:http://comercial.ciren.cl/index.php?option $=$ com $_{-}$ $\mathrm{k} 2 \&$ view $=$ item\&layout $=$ item\&id $=91$ Revisado en septiembre, 2015.

CORFO (1950). Geografía Económica de Chile. Tomo I y II. Santiago de Chile: Fundación Pedro Aguirre Cerda. 
CORFO (1960). Geografía Económica de Chile. Tomo III y IV. Santiago de Chile: Fundación Pedro Aguirre Cerda.

Correa, L., \& Salas, A. (2015) Gobernabilidad, Seguridad y Desarrollo en las Zonas Extremas de Chile. Santiago: Academia Nacional de Estudios Políticos y Estratégicos.

Craviotti, C. (2014). Agricultura familiar-Agronegocios: Disputas, interrelaciones y proyectos. Territorios, 30, 17-37.

Chonchol, J. (1952). Informe sobre las posibilidades de integrar más plenamente las provincias de Aisén y Chiloé Continental a la Economía Nacional. Dirección de Tierras y Colonización, Santiago de Chile.

FAO. (2014). ¿Qué es la agricultura familiar? Disponible en http://www.fao.org/family- farming-2014/home/ what-is-family-farming/es/ Revisado en marzo, 2015.

Gobierno Regional de Aysén (2011). Plan Regional De Ordenamiento Territorial: Región de Aysén. Coyhaique.

Haesbaert, R. (2004). O mito da Desterritorializaçao. Do "fin dos territorios" à multiterritorialidade. Río de Janeiro: Editorial Bertrand.

Harvey, D. (2004). Spaces of Capital towards a Critical Geography. New York: Routledge.

Harvey, D. (2014). Diecisiete contradicciones y el fin del capitalismo. Quito: Editorial IAEN.

Ibar, J. (1973). Aisén. Hombres y naturaleza. Valparaíso: Imprenta de La Armada.

Lapes De Souza, M. (2000). O Território: Sobre Espaço e Poder, Autonomia e Desenvolvimento. En E. De Castro, G. Da Costa \& L. Corrêa (Eds.), Geografia: Conceitos e Temas (pp. 77-116). Río De Janeiro: Editorial Bertrand.

Larsen, P. (2015). Derechos indigenas, gobernanza ambiental y recursos en la Amazonía Peruana. Hacia una antropología de la posfrontera. Lima: IEP.

Mandujano, F., \& Rodríguez, J. C. (2016). La catástrofe del 2008 en la provincia de Palena: reflexiones sobre sus particularidades e impacto en la Patagonia Occidental. Magallania, 44(2), 69-85.

Manzanal, M. (2007). Actores rurales y negociaciones en el norte Argentina. En J. Bengoa (Ed.), Territorios rurales: movimientos sociales y desarrollo territorial en América Latina (pp. 482-496). Santiago de Chile: Catalonia.

Martinic, M. (2005). De la Trapananda al Aysén. Una mirada reflexiva sobre el acontecer de la Región de Aysén desde la Prehistoria hasta nuestros días. Santiago de Chile: Pehuén Editores.

Masalleras, M., \& Ortega, R. (2012). Fronteras interiores; Una contribución del ejército vigente. Memorial del Ejército de Chile (488) (pp. 135-147). Santiago de Chile: D. C. Ejército.

Migdal, J. (2008). Estudiar al Estado. Revista Académica de Relaciones Internacionales, 8, Migdal, J. (2011). Estados débiles, Estados fuertes. México: Fondo de Cultura Económica.

GERI-UAM. http://www.relacionesinternacionales.info/ojs/ article/viewFile/110/102.html

Ministerio de Defensa Nacional (2010). Libro de la Defensa Nacional, Santiago de Chile.

Ministerio de Salud (2015). Distribución de farmacias por región. Situación a diciembre de 2014. Santiago de Chile.

Mora-Delgado, J. (2008). Persistencia, conocimiento local y estrategias de vida en sociedades campesinas. Revista de Estudios Sociales, 29, 122-133.

Rodríguez, J., Gissi, N., Ther, F., \& Medina, P. (2012). La Patagonia en escena: Auge minero, demanda energética y geopolítica del neoliberalismo. Trabajo presentado en el Congreso Chileno de Sociología 2012, Pucón. Disponible en: http://sociologiadesarrollo.wordpress. com/2012/10/30/7-congreso-chileno-de- sociologiapucon-2012/ Revisado en Agosto, 2013.

Rodríguez, J., Gissi, N., \& Medina, P. (2015). Lo que queda de Chile: La Patagonia, el nuevo espacio sacrificable. Revista Andamios, 12(27), 335-356.

Rodríguez, J., Reyes, S., \& Mandujano, F. (2016). Reconfiguración espacial y modelos de apropiación y uso del territorio en la Patagonia chilena: migración por cambio de estilo de vida, parques de conservación y economía de la experiencia". Revista de Geografía Norte Grande, 64, 187-206.

Rodríguez, J., Mandujano, F., \& Vargas, R. (2018). Ruralidad, conservación y justicia territorial. Legitimidades desiguales en la Patagonia Norte chilena. Revista Austral de Ciencias Sociales, 35, 155-181

Saavedra, G. (2007). Economías silenciosas del litoral aisenino. En M. Osorio, G, Saavedra\& H. Velásquez (Eds.), Otras narrativas en Patagonia: tres miradas antropológicas a la Región de Aysén (pp. 11-18). Santiago de Chile: Nire Negro.

Sáenz, J. (2015). Territorio rural y sus transformaciones ante procesos de globalización en la subregión transandina de la Provincia de Palena, Patagonia chilena. Memoria para optar al título de Antropólogo, Departamento Antropología, Universidad de Chile.

Salas, H., Rivermar, L., \& Velasco, P. (2011). Nuevas Ruralidades. Expresiones de la transformación rural en México. México, DF: UNAM-IIA-Juan Pablos Editor, 
Santos, M. (2000). La naturaleza del espacio. Técnica y tiempo. Razón y emoción. Barcelona: Ariel.

Sassen, S. (2015). Expulsiones. Brutalidad y complejidad en la economía global. Buenos Aires-Madrid: Ed. Katz.

Schejtman, A., \& Berdegué, J. (2003). Desarrollo Territorial Rural. En R. Echeverría (Ed.), Desarrollo territorial rural en América Latina y el Caribe. Washington DC: Banco Interamericano de Desarrollo.

SERNAPESCA (2015). Boletín Sectorial N¹. Aysén.

Silva, V. (1936). La tempestad se avecina. Santiago de Chile: Zig Zag.

Steffen, H. (2015). Problemas limítrofes y viajes de exploración a la Patagonia. Recuerdos de la época del conflicto fronterizo entre Chile y Argentina. Santiago de Chile: DIBAM.

SUBDERE (2008). Actualización Estudio Diagnóstico y Propuestas para Territorios Aislados. Disponible en: http://www.subdere.cl/1510/articles-74158_ recurso_1.pdf Revisado en Mayo, 2013.

Villagran, J., Núñez, A., \& Hidalgo, R. (1997), Políticas públicas y Ocupación del Territorio en la XI Región de Aysén. Revista de Geografía Norte Grande, 24, xx-xx.

Wolf, E. (1971). Los Campesinos. Barcelona: Editorial Labor S.A. 